\title{
PANORAMA ACTUAL DE LA CONSTRUCCION MIXTA
}

\author{
(PRESENT OVERVIEW OF COMPOSITE CONSTRUCTION)
}

Julio Martínez Calzón, Dr. Ing. de Caminos

Fecha de recepción: $5-\mathrm{XII-88}$

560-31

RESUMEN

Se lleva a cabo una exposición de la actividad de la construcción mixta en los últimos años, señalando dentro de los temas teóricos y de diseño las diferentes alternativas seguidas en Europa Occidental, Estados Unidos y Japón, tomando como referencia básica los resultados de la Conferencia Internacional llevada a cabo sobre el tema en Henniker, New Hampshire, en junio de 1987.

Asimismo, se efectúa una exposición de los principales tipos estructurales de puentes mixtos diseñados muy recientemente y se aboga por una mayor coordinación en la investigación y normativa relativas a la construcción mixta, tomando en consideración los problemas especificos de la misma: complejidad constructiva; interacción muy variable con el pretensado en función de los valores reales del módulo de elasticidad del hormigón, abolladura de sistemas mixtos, etc., en orden a lograr un aprovechamiento total y seguro de las amplias posibilidades de los sistemas mixtos en el ámbito de las grandes construcciones.

\section{SUMMARY}

An account is given of composite construction activity over recent years, showing the various alternatives in the areas of theory and design pursued in Western Europe, the United States and Japan, based on the results of the International Conference held on the topic in Henniker, New Hampshire, in 1987.

Also, a description is given of the main structural types of very recently-built composite bridges, advocating greater coordination of research and regulation standards relating to composite construction, bearing in mind the particular problems involved; construction complexity; extremely variable interaction with presstressing, proportional to the real values of the concrete modulus of elasticity; formation of irregularities in mixed systems, etc., aiming at taking full and guaranteed advantage of the extensive possibilities of composite systems in the context of large construction operations.
Desde la publicación del Libro "Construcción Mixta. Hormigón-Acero" (1), con el cual se podía conocer con precisión la situación en el campo de la Construcción Mixta, ha transcurrido una década. El presente articulo pretende ofrecer una visión de las líneas fundamentales: conceptuales, teóricas, constructivas, etc., que se han desarrollado en este intervalo, para tratar de actualizar el conocimiento de la situación a los técnicos no implicados directamente en el tema o completarlo a aquellos que, aun sintiéndose vinculados a este tipo de técnica - como preferente, o como una más en el bagaje que el técnico posee para resolver los problemas estructurales, preferentemente en el ámbito de los puentes de cierta importancia y en los edificios con potentes condicionantes constructivos, dimensionales o cronológicos - no hayan podido seguir en detalle el proceso evolutivo de esta tecnología.

Aunque se han producido otras reuniones vinculadas con esta técnica (2), la más importante confrontación del estado de la cuestión tuvo lugar el pasado año en una reunión internacional mantenida en Nueva Inglaterra (3) bajo el patrocinio de la Engineering Foundation, American Society of Civil Engineers (ASCE) y la Asociación Internacional de Puentes y Estructuras (IABSE), de cuyos principales temas y resultados la ASCE ha publicado recientemente un volumen resumen (4) que ofrece una visión ajustada de la situación de la Construcción Mixta.

La falta de estructura oficial como pais en esta actividad - como en otros campos - ha hecho que la participación española fuera tardia y particular, no pudiéndose incorporar a dicha publicación las aportaciones preparadas al efecto por Francisco Millanes y el autor de este artículo (5) y por la Cátedra de Estructuras de Arquitectura de la Universidad Politécnica de Madrid (6), aunque la primera de ellas será en breve publicada por ASCE en uno de sus boletines ordinarios, con la calificación de gran interés. 
La exposición se va a dividir en dos líneas principales:

- Investigación, Teoría y Normativa, por un lado;

- Diseño, Innovaciones y Tendencias, por otro,

$y$, a su vez, se considera necesario subdividir la presentación en áreas geográficas diferenciadas: Europa, USA y Japón, puesto que determinan formas de actuación tan diferentes que requieren una visión separada. En ciertos casos existen aportaciones sencillas aisladas, como en el caso de Australia, pero poco significativas.

\section{Investigación, Teoría y Normativa}

Los aspectos fundamentales del esfuerzo investigador no se han centrado, sino todo lo contrario, en una línea consecuente o predeterminada de apoyo y contras. te de los diversos esfuerzos, dando lugar, por tanto, a una total dispersión y aleatoriedad de los trabajos y produciéndose repeticiones, tendencias contrarias en ámbitos ya resueltos prácticamente, e incluso ensayos considerados innovadores cuyas premisas habian sido empleadas de forma completa en obras importantes realizadas con anterioridad en otros paises ( $\left.{ }^{\star}\right)$, lo que claramente pone de manifiesto la falta de coordinación internacional en la investigación, y que las reuniones antedichas tratan de paliar, aunque levemente, dada la gran disparidad de criterios existente en las tres áreas geográficas indicadas y que se tratará de señalar en el siguiente análisis expositivo.

\section{Europa}

Las reuniones mantenidas a lo largo de muchos años por miembros de diferentes paises europeos para la preparación y culminación de unas Recomendaciones conjuntas CEB, FIP, CECM, IABSE (*)), (7), que cristalizaron posteriormente, con ligeros retoques en el Eurocódigo 4 (8) (difundido prácticamente el año 1987, aunque con rango de provisionalidad hasta su edición final prevista en 1989), han servido para que, aun con notables diferencias en el detalle y aplicación de las diferentes posibilidades de la Construcción Mixta, se haya alcanzado un grado de unificación conceptual importante, basado en el empleo consecuente y activo del

(*) Puede verse a este respecto el trabajo "Laboratory Tests of a Continuous Composite Bridge" de Mark Moore e Ivan M. Viest de la ASCE, pág. 472 y ss. (4), que reproduce con total precisión el proceso de pretensado antes de la conexión, realizado en el Puente de Juan Bravo en Madrid en 1970. Proyecto del autor de este artículo.

(**) Comité Europeo del Hormigón, Federación Internacional de Pretensado, Convención Europea de la Construcción Metálica y Asociación Internacional de Puentes y Estructuras.
Análisis en Estados Límites, en una línea claramente operativa y positiva. Considero $-y$ no sólo porque se integre en la línea de criterios y planteamientos ya elegidos en (1) y en el resto de la actual normativa estructural española, sino porque permite un enfoque riguroso de toda la cuantiosa problemática contenida en la construcción mixta, al tratar de armonizar los aspectos de las técnicas del hormigón pretensado y la construcción metálica - que dicha línea de actuación, complementada poco a poco con criterios y procesos del análisis no lineal más riguroso, puede llegar a lograr una ajustada y correcta utilización del potencial contenido en la construcción mixta.

Pero no por ello quiere decirse que no existan en la actividad investigadora y teorética europea divergencias y contrasentidos. En absoluto; existen y posiblemente serán difíciles de eliminar en breve plazo por las notables diferencias globales existentes en cada país, pero están sentadas unas bases para una actuación unificadora y activa que reduzca la incidencia de tales circunstancias.

Los temas que han sido objeto de mayor actividad investigadora en Europa, se refieren básicamente a los puentes, y pueden citarse preferentemente los siguientes:

- Influencia del grado de conexión; deslizamientos y criterios de posicionamiento y distribución.

- Incidencia de la fatiga y efectos dinámicos en la conexión.

- Evaluación de las redistribuciones por deslizamientos de la conexión y por fisuración.

- Compatibilidad de deformaciones para la plena garantía del análisis elastoplástico. Validez en secciones esbeltas y semicompactas,

que pueden seguirse de forma activa en las referencias (9) a (15).

Por el contrario en el ámbito de la edificación no se han llevado a cabo trabajos notables de carácter generalizador, aunque se hayan producido interesantes soluciones aisladas y particularizadas, a excepción de los trabajos relativos al estudio de uniones semirrígidas en nudos de pórticos (16).

En el ámbito de la normativa, además del Eurocódigo 4 ya reseñado que puede servir de documento centralizador de la actividad, se ha producido la publicación de un número apreciable de Instrucciones nacionales entre las que cabria destacar: Inglaterra (16); Alemania (17); Suiza (18); Austria (19); Francia (20) e incluso Australia (21), en las que se tratan numerosos aspectos no 
contenidos en el Eurocódigo que definen condiciones importantes de la construcción mixta.

\section{USA y Canadá}

En el ámbito de los puentes mixtos la actividad investigadora está claramente estancada y vertida hacia la reiteración de los modelos y propuestas de diseño ya de uso corriente, tratando de mejorar aspectos y corregir defectos observados en tales modelos a lo largo de los pasados años.

Por el contrario, en el ámbito de la edificación ha habido una notable preocupación por incrementar el conocimiento del comportamiento de las estructuras mixtas en dos aspectos principalmente:

- Nudos elásticos en entramados de pórticos. Ductilidad.

- Empleo de losas de forjado mixtas mediante chapa plegada, conectadas a las vigas principales; $y$ combinadas con el empleo de alveolos en las almas, o vigas peraltadas o realzadas, etcétera,

que como en casos anteriores pueden seguirse en las referencias (22) a (24).

$Y$, coincidentemente, este mismo panorama se refleja en la Normativa publicada en este periodo: mínima, en el caso de puentes (25), y limitada a la transformación de los métodos de cálculo en tensiones admisibles en estados límites; y de cierta amplitud en sistemas mixtos para edificios, referencias (26) a (29).

\section{Japón}

Quizá sea este país el que ha llevado a cabo en esta última década el esfuerzo investigador más señalado en el ámbito de la construcción mixta, sobre todo en los sistemas aplicables a edificios. Sin embargo, el empleo de métodos de análisis basados en criterios de tensiones admisibles, y el hecho de que sus reglamentos incluyen unos condicionantes mínimos muy exigentes para garantizar un comportamiento estructural adecuado frente a las solicitaciones sísmicas requeridas, hace que las dimensiones y resultados de sus ensayos sean muy dificiles de adaptar y comparar con las soluciones europeas y americanas.

Las líneas de trabajo que han venido desarrollando son muy numerosas y se refieren básicamente $a$ :

- Soportes mixtos, principalmente recubiertos.

- Nudos viga-soporte, principalmente mixtos recubiertos, bajo solicitaciones dinámicas, cíclicas y de fatiga.
- Pantallas mixtas para aplicaciones antisísmicas,

habiendo presentado en la Conferencia de Henniker (3) una gran cantidad de trabajos y referencias recogidas adecuadamente en (4).

Resumiendo todo lo anterior, y desde una perspectiva exigente, podria considerarse que el avance teorético experimentado por la construcción mixta en esta década resulta poco señalado, dando lugar a que los principios y criterios generales desarrollados en la obra inicialmente citada (1) contengan en forma eficiente la mayor parte de lo que se requiere para el entendimiento, análisis y control preciso de la construcción mixta actual, con los lógicos complementos ya citados relativos a detalles y análisis de problemas locales de conexión, alveolos y rigidización.

Y, más aún, considero incluso que los problemas conceptuales reales y profundos que la construcción mixta plantea, que se diferencian de los análogos en las técnicas del hormigón pretensado y la construcción metálica, no han sido puestos de manifiesto y resultan en cierta forma claves para impulsar el valor potencial de la construcción mixta haciendo progresar su conocimiento. Así, resulta claro que la gran complejidad de los aspectos analiticos derivados de la multiplicidad de los esquemas de diseño y proceso constructivo requieren planteamientos de cálculo rigurosos y automatizados, y no simples formulaciones prácticas, válidas. quizá, aunque muy limitadamente, para casos sencillos que no se separen demasiado de las piezas simplemente apoyadas; resultando obligado el estudio evolutivo de la configuración constructiva cuando el sistema estructural se sale de lo elemental, poniéndose entonces de manifiesto aspectos propios y determinantes que la investigación deberia precisar e incorporar a la normativa de la construcción mixta.

Así, por ejemplo, el postesado a edades tempranas del hormigón, que en las estructuras de hormigón pretensado no se diferencia notablemente del efectuado a edades más avanzadas, determina muy esencialmente el estado tensional de una sección mixta, necesitándose una clara evaluación del módulo de elasticidad $E_{c t}$ en dichas edades tempranas, sobre todo cuando se sabe que tales valores no están bien precisados - sino todo lo contrario- en las normas vigentes.

Para esclarecer estas diferencias, en la figura n. ${ }^{\circ} 1$ se muestra el comportamiento a fisuración de la sección mixta indicada en la figura n. ${ }^{\circ} 2$, considerando diferen. tes valores del módulo de elasticidad del hormigón de las losas superior e inferior, y se comparan con los correspondientes a una sección ideal de hormigón pretensado equivalente; es decir, que no presente acero estructural ni en el ala superior ni en las almas. 


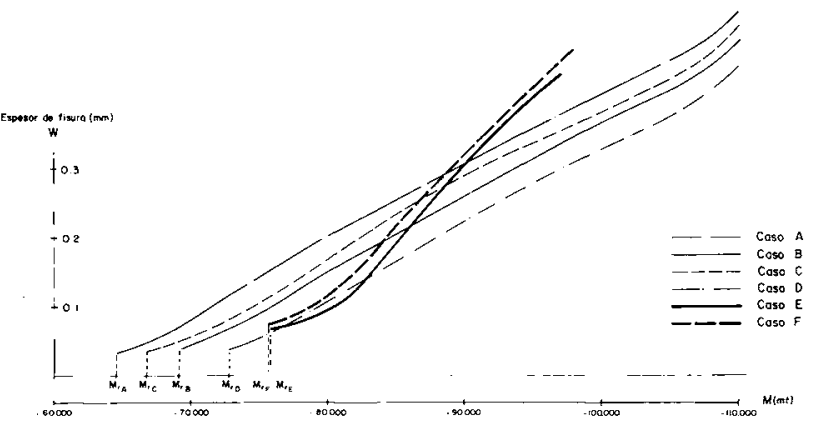

Fig. 1

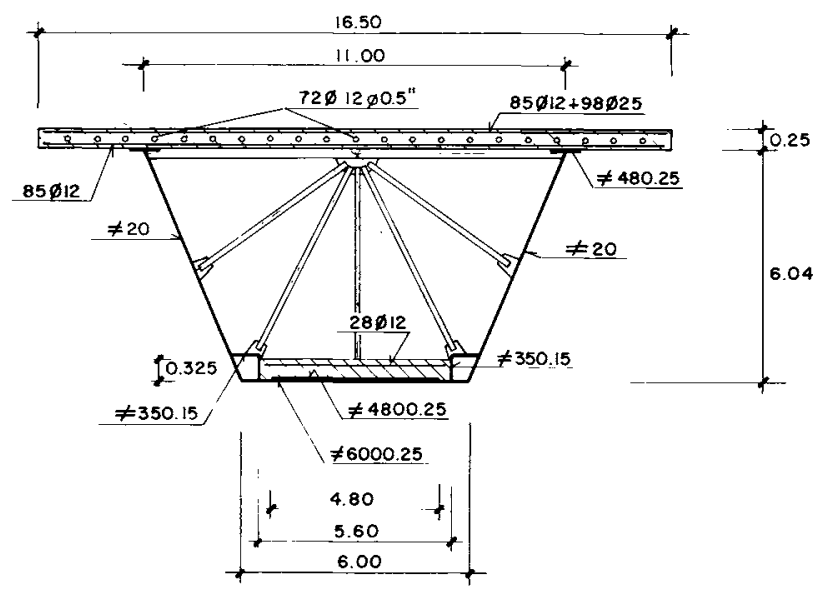

Fig. 2

Se han considerado para un hormigón de resistencia caracteristica fck $=350 \mathrm{kp} / \mathrm{cm}^{2}$ cuatro valores del módulo de elasticidad de la losa superior en el instante de pretensado: $\alpha \sqrt{\text { fck; }}$ y dos valores del módulo de elas-

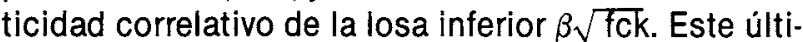
mo valor se consideraba posteriormente para ambos hormigones en la fase de aplicación de las demás acciones. Los casos estudiados han sido:

\section{Secciones mixtas}

$\begin{array}{lll}\text { Caso A } & \alpha=10000 & \beta=14000 \\ \text { Caso B } & \alpha=12000 & \beta=14000 \\ \text { Caso C } & \alpha=14000 & \beta=19000 \\ \text { Caso D } & \alpha=19000 & \beta=19000\end{array}$

\section{Secciones pretensadas}

$$
\begin{array}{ll}
\text { Caso E } & \alpha=\beta=14000 \\
\text { Caso F } & \alpha=\beta=19000
\end{array}
$$

tratando de estimar las diferencias entre las situaciones reales de pretensado a edades tempranas (caso A) y las teóricas señaladas en las instrucciones, que se corresponderían con las reales en las que el pretensado se efectúa a edades más tardías.
Como es lógico, la incidencia de $\alpha$ en las secciones mixtas es muy apreciable, dado que una gran parte del pretensado se incorpora a la sección de acero estructural (las tensiones que resultan en este material en el instante de tesado son:

$$
\begin{aligned}
\sigma_{\mathrm{SA}} & =-2.178 \mathrm{kp} / \mathrm{cm}^{2} \\
\sigma_{\mathrm{SB}} & =-1.961 \mathrm{kp} / \mathrm{cm}^{2} \\
\sigma_{\mathrm{SC}} & =-1.782 \mathrm{kp} / \mathrm{cm}^{2} \\
\sigma_{\mathrm{SD}} & =-1.453 \mathrm{kp} / \mathrm{cm}^{2}
\end{aligned}
$$

que claramente señalan la importancia de conocer con precisión $E_{c}$ en el instante de pretensado ya que puede influir apreciablemente en problemas de abolladuras locales del acero estructural en dicha fase) lo cual hace que los momentos de fisuración bajo solicitaciones a tiempo inicial sean sensiblemente diferentes:

$$
\begin{array}{ll}
\mathrm{M}_{\mathrm{rA}}=-64.490 \mathrm{mt} . & \mathrm{M}_{\mathrm{rB}}=-69.058 \mathrm{mt} \\
\mathrm{M}_{\mathrm{rC}}=-66.772 \mathrm{mt} & \mathrm{M}_{\mathrm{r} \mathrm{C}}=-73.137 \mathrm{mt}
\end{array}
$$

Una vez fisurada la sección, los espesores de fisura se mantienen muy controlados por el acero estructural dentro del conjunto de la sección cuya rigidez fisurada no desciende de manera excesiva.

Por el contrario, en las secciones pretensadas, aun cuando los momentos de fisuración son más altos - por aprovecharse más favorablemente la incidencia directa del pretensado-: $\mathrm{M}_{\mathrm{rE}}=-76.957 \mathrm{mt} ; \mathrm{M}_{\mathrm{rF}}=$ $=-75.657 \mathrm{mt}$; el progreso de la fisuración es mucho más rápido, debido a la gran pérdida de rigidez de la sección fisurada respecto a la inicial.

En la figura $n . .^{\circ} 3$ se analiza el caso $C$ para las situaciones de aplicación de sobrecargas a tiempo infinito, observándose la incidencia que presenta el valor de la solicitación inicial permanente aplicada tras el pretensado, en la determinación del momento de fisuración.

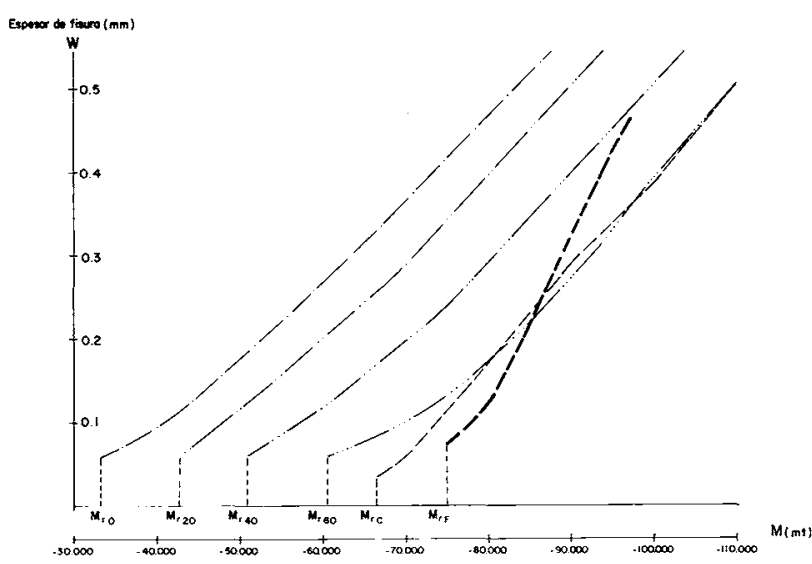

Fig. 3 
Así para:

$$
\begin{array}{ll}
M_{c p}=0 & M_{r \infty}=-33.705 \mathrm{mt} \\
M_{c p}=-20.000 \mathrm{mt} & M_{r \infty}=-42.632 \mathrm{mt} \\
M_{c p}=-40.000 \mathrm{mt} & M_{r \infty}=-51.590 \mathrm{mt} \\
M_{c p}=-60.000 \mathrm{mt} & M_{r \infty}=-60.517 \mathrm{mt}
\end{array}
$$

pero en todos los casos el progreso posterior de la fisuración es semejante al deducido para $t=0$, en la línea genérica de fisuración contenida por el acero estructural.

Esta clara diferencia en el comportamiento postfisuración entre sistemas mixtos y sistemas pretensados señala la necesidad de establecer criterios precisos, no sólo en la evaluación de $\mathrm{E}_{\mathrm{ct}}$, sino en los criterios de aplicación de las clases I, II y III en las estructuras mixtas, que deben ser diferentes a los que se señalan en las Instrucciones de Hormigón pretensado.

El empleo de secciones mixtas dobles, con losas de hormigón en la parte inferior de las piezas mixtas en las zonas de momentos negativos, llevan también de la mano la necesidad de establecer con propiedad los criterios de rigidización de las chapas metálicas colaborantes en dichas zonas. Es claro que la compresión existente determina un carácter ultrarrígido para cualquier rigidizador de la chapa incorporado a la sección de hormigón. Asimismo la adherencia y empotramientos locales favorecen las condiciones resistentes del panel aislado frente a la abolladura.

Aspectos adicionales tales como la evaluación de las condiciones reales de deformación y distorsión de las vigas cajón semicerradas cuando se combinan con losas prefabricadas o semiprefabricadas, importantes para evaluar los contragiros de ejecución en puentes curvos o con claras acciones disimétricas de montaje, y evitar defectos apreciables en la geometría aparente de la obra; asi como otras diversas posibilidades poco analizadas, ponen de manifiesto la necesidad de proseguir con una apropiada y coordinada línea investigadora y teórica.

\section{Diseño, Innovaciones y Tendencias}

También en esta actividad se producen claras diferencias en las pautas y modelos de estudio.

\section{Europa}

La evidente necesidad en muchas áreas superpobladas, por saturación de ciertas zonas semiurbanas, de un tercer nivel viario para las recientes soluciones de transporte rápido, que requieren radios y pendientes limitadas, determinan la exigencia de grandes estructuras capaces de superar sin interacciones los dos niveles inferiores: el natural y el inmediato superior creado por la actividad ya existente. Estas grandes luces, combinadas con las exigencias de pequeños movimientos, giros menores de 0,0015 rad y flechas inferiores a $L / 2.000$-debido a las sofisticadas técnicas empleadas en la alta velocidad - y una gran garantía de correcta conservación, han vuelto a situar a los siste. mas mixtos como fuente de soluciones apropiadas, ya que las estructuras pretensadas -independientemente de los agudos problemas de conservación que se han detectado en una gran parte de las estructuras realizadas no ha mucho tiempo-dan lugar a pesos y procesos constructivos de menor viabilidad.

Los sistemas que se están desarrollando corresponden básicamente a grandes sistemas de viga cajón, con losas de hormigón tanto en el tablero superior como en el fondo del mismo en ciertas zonas, y al campo de las grandes celosias mixtas, combinadas o no con el empleo del pretensado externo y la utilización de doble cabeza de hormigón, según se trate de sistemas continuos o isostáticos.

El empleo del pretensado longitudinal interno de la losa superior ha quedado prácticamente desechado y se decanta inicialmente por el empleo de armaduras pasivas con adecuados recubrimientos (Alemania) o por potentes pretensados externos (Francia y Suiza) debidamente ubicados en los amplios espacios que ofrecen los cajones y celosias de gran canto.

Seguidamente se ofrecen algunas de las soluciones más llamativas, realizadas o en curso, en las que se detallan algunas características locales más precisas relativas a esta gama de soluciones.

\section{Puente de Nesenbach (30)}

El cordón superior de la celosía se embebe en la losa de hormigón, y se hacen coincidir los centros de gravedad de ambos elementos, manteniendo en todo momento las acciones centradas, sin flexiones secundarias. Las cargas entre nudos se transfieren también por acción mixta de dicho cordón superior.

En otras soluciones (puentes de Neckar; Isar Gro $\beta$ Hesselohe; etc.) el cordón superior se realiza con la losa apoyando superiormente en la celosía, haciendo coincidir la intersección de diagonales con el centro de gravedad de la sección mixta global del cordón superior. Aunque la ejecución de este elemento es, por ello, más simple, durante la fase de montaje y hormigonado de la losa la estructura metálica presenta excentricidades en su cordón superior con flexiones secundarias de cierta importancia. 

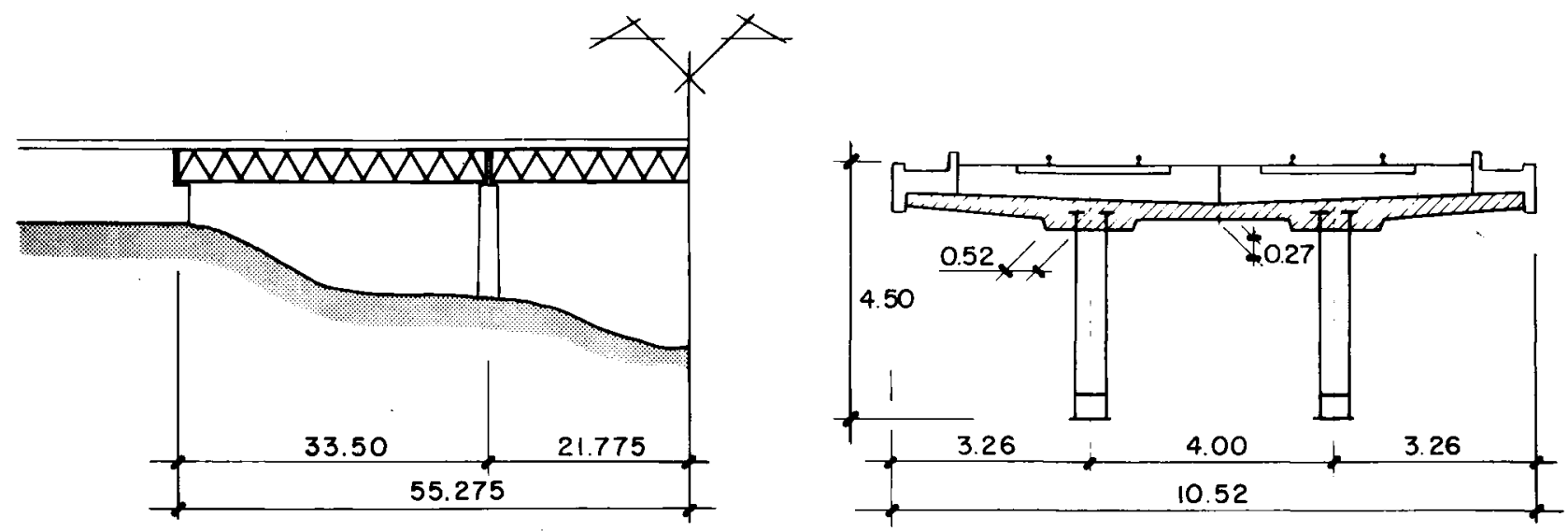

Puente de Nesenbach
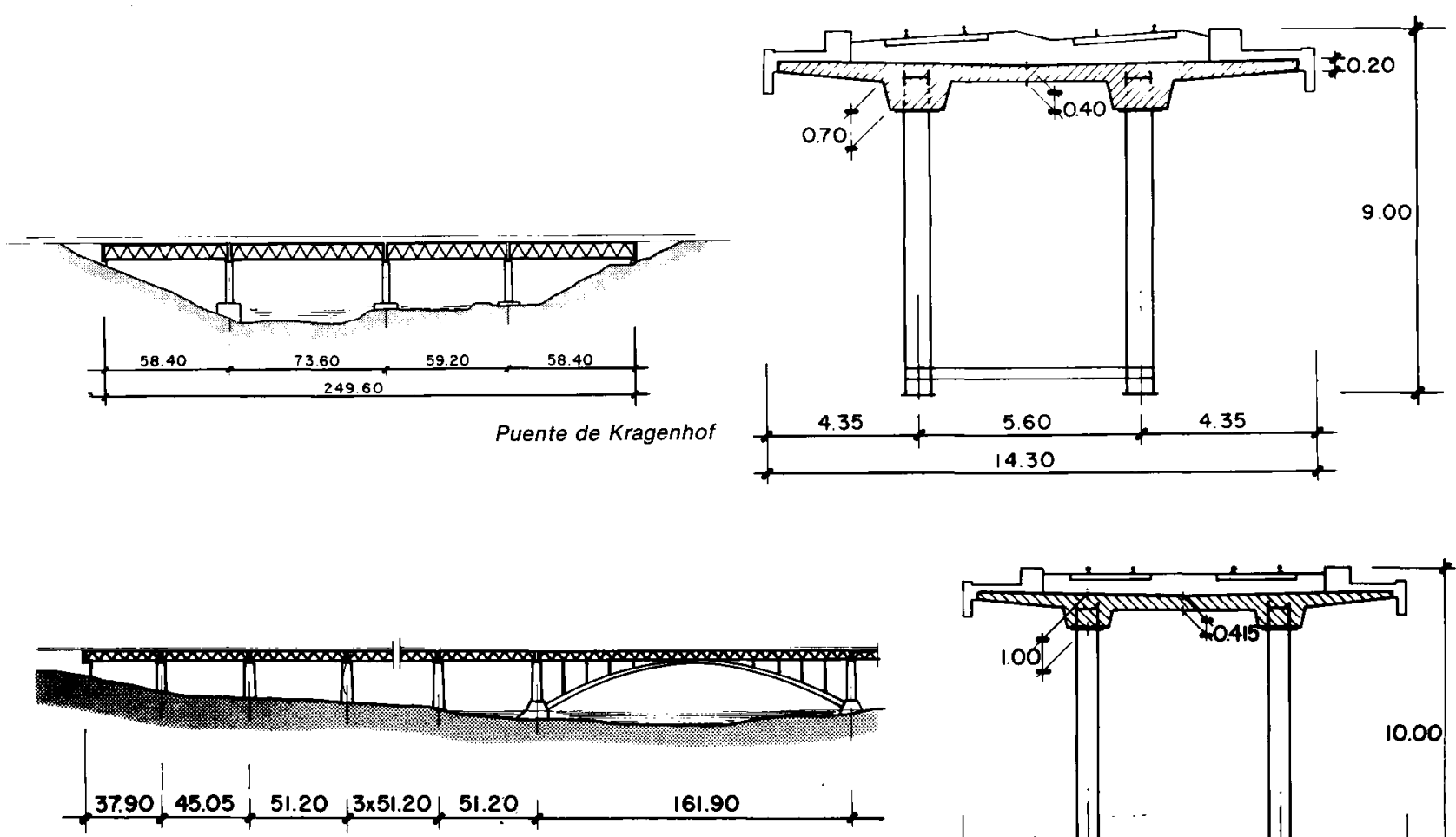

Puente de Veitshöcheim

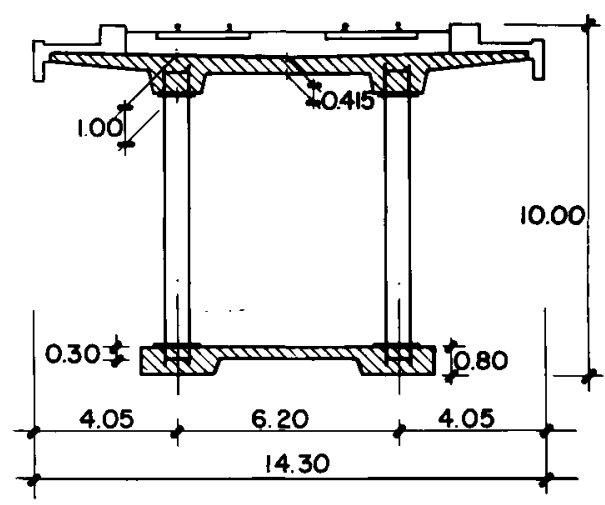

\section{Puente de Kragenhof (31)}

La solución del cordón superior es análoga a la del ejemplo anterior. El sistema se montó por empuje de la celosia metálica actuando como viga continua provisional. La celosia deslizaba sobre los soportes apoyando exclusivamente en nudos de la misma, lo cual requería un sistema especial de elementos que se acoplaban a los nudos al entrar en la zona de dicho deslizamiento. Finalizado el montaje se efectuaba la construcción de la losa con la condición de viga continua de la celosía mantenida y sólo tras el endurecimiento de la losa se procedia al desbloqueo de la continuidad, para transformarse el sistema definitivo en cuatro piezas isostáticas. El puente en planta presenta una ligera curvatura $R=1.552 \mathrm{~m}$ para $V \max =160 \mathrm{~km} / \mathrm{h}$.

\section{Puente de Veitshöcheim (32)}

En este ejemplo el cordón inferior incluye una losa de hormigón con pretensado interno longitudinal que comienza a actuar al final del proceso de ejecución frente a cargas muertas y sobrecargas de uso, en vanos simples sobre pilas y en continuidad elástica sobre el arco. 


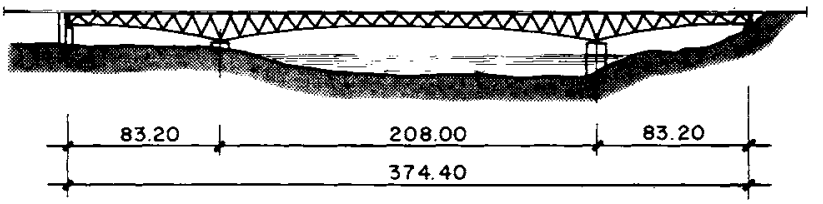

Puente de Nantenbach

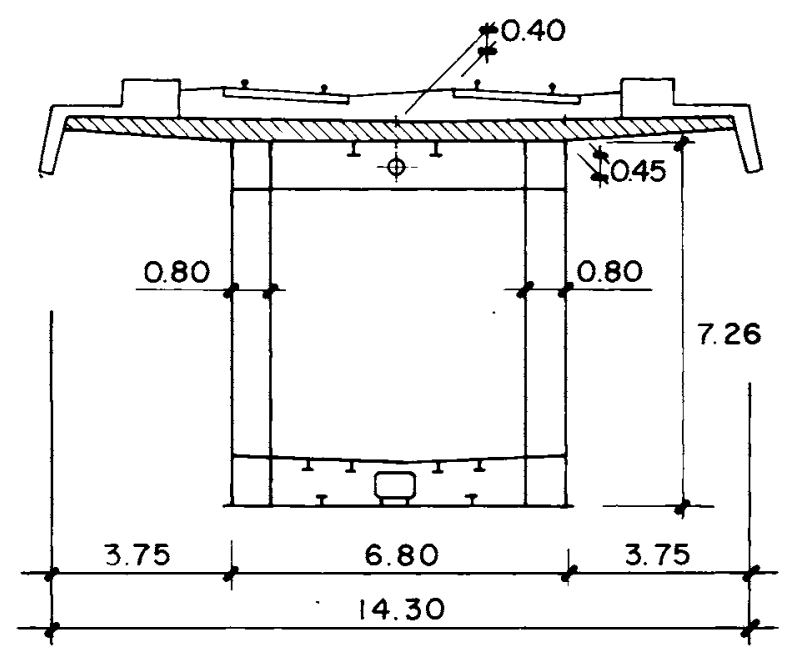

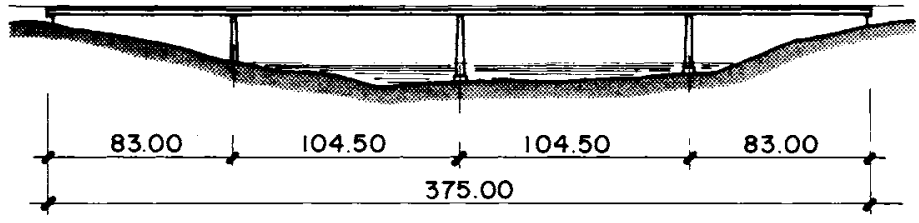

Puente de Wasserburg
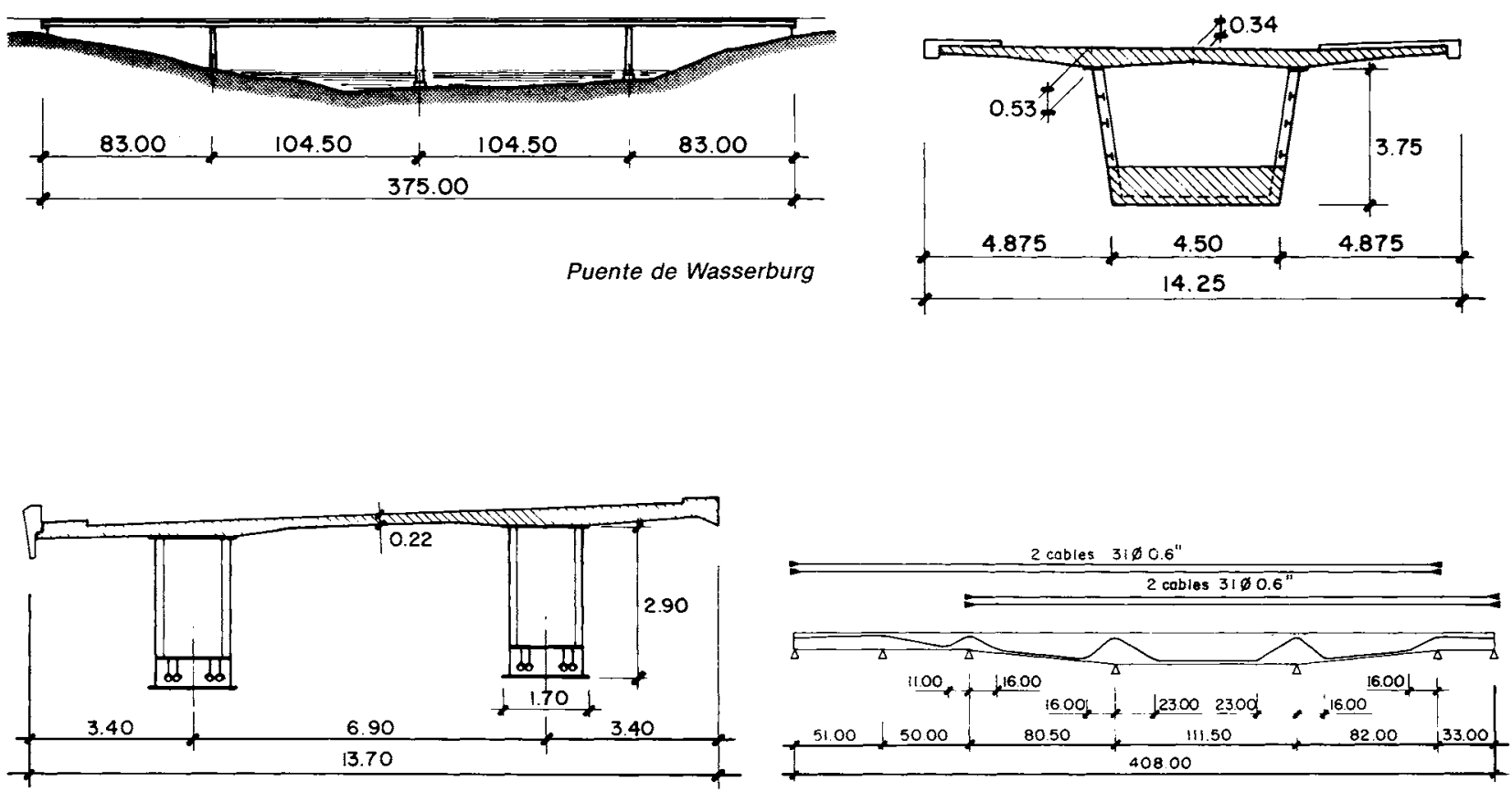

Puente de Chandoline sobre el Ródano

\section{Puente de Nantenbach (33)}

Dintel de celosia mixta continua con canto variable y losa de hormigón inferior en las zonas de momentos negativos, para ferrocarril de $V=250 \mathrm{~km} / \mathrm{h}$.

\section{Puente de Wasserburg (32)}

Puente de carretera continuo con losa inferior de hormigón en las zonas de momentos negativos.

(c) Consejo Superior de Investigaciones Científicas Licencia Creative Commons 3.0 España (by-nc)

\section{Puente de Chandoline sobre el Ródano (34)}

Puente doble de viga continua con pretensado externo mediante cuatro cables enfundados en vainas de polietileno e inyección de grasa. El pretensado es parcial de manera que la losa está comprimida bajo las acciones permanentes y parte de las sobrecargas exclusivamente.

Otros puentes mixtos con estos conceptos de pretensado externo se encuentran actualmente en fases de proyecto y construcción.

http://informesdelaconstruccion.revistas.csic.es 


\section{Viaducto de Maupré en Charolles (33)}

Este singular puente incluye como almas un sistema de chapa plegada de $8 \mathrm{~mm}$ de espesor, así como un pretensado externo incluido dentro de la célula triangular. Debido a la pequeña rigidez longitudinal de dichas almas los esfuerzos de pretensado se incorporan básicamente al tablero. El relleno del tubo mediante hormigón tiene básicamente un carácter estabilizador de la chapa del mismo.
Dada la novedad de la sección, con dificultades importantes en el proceso de ejecución, se está prosiguiendo la investigación teórica y en obra sobre el comportamiento de la misma.

Las realizaciones llevadas a cabo por otros paises europeos, aunque notables, no presentan innovaciones especificas y corresponden fundamentalmente al campo de las variantes constructivas.

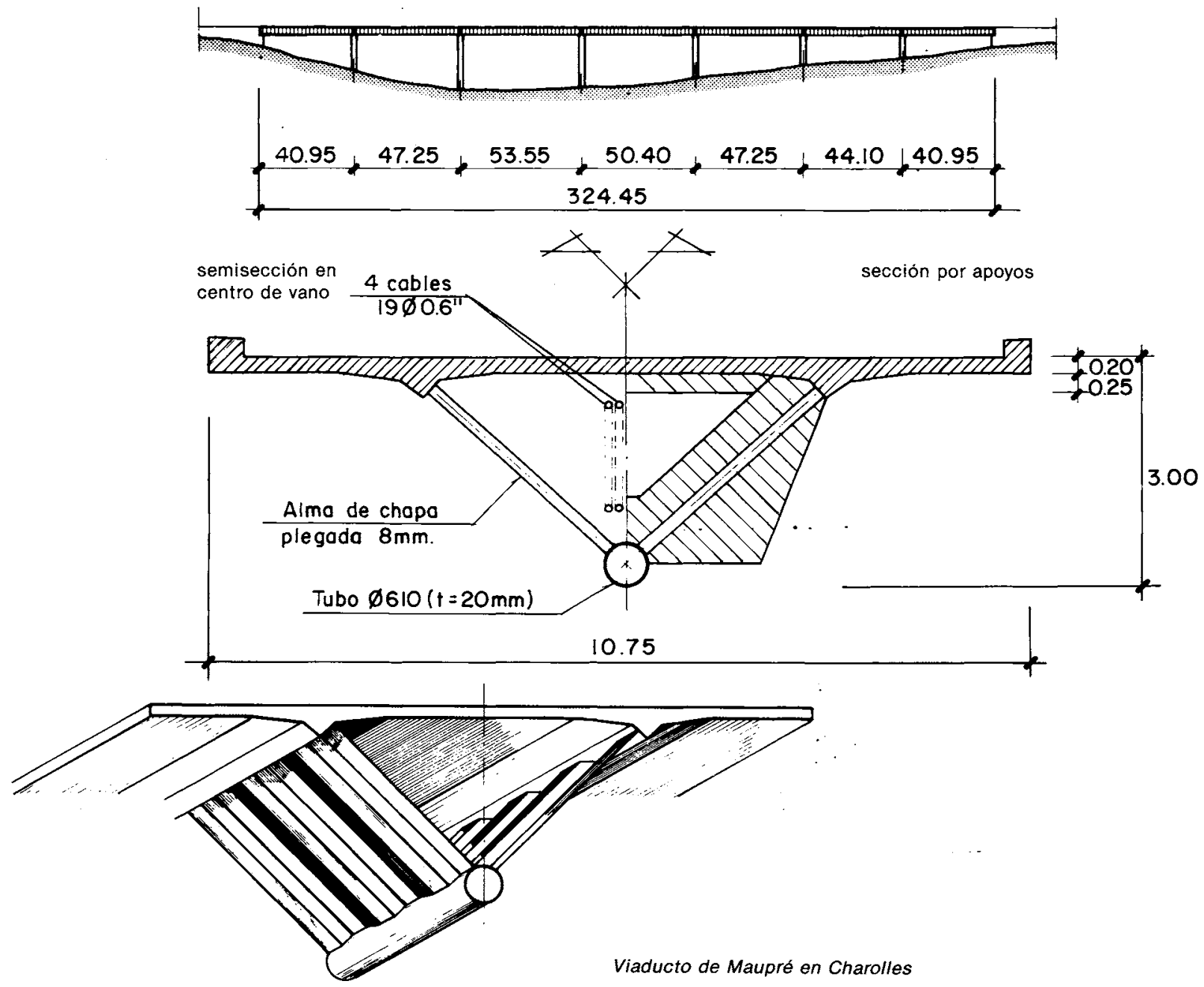

Personalmente, y como aportación española a lo largo de esta decáda, he proyectado, entre otras, cuatro estructuras que - dentro de la relativa modestia de dimensiones que nuestra infraestructura requiere - ofrecen algunas soluciones perfectamente integradas en el empleo de novedades reseñado.

\section{Puente de Ciervana en el Superpuerto de Bilbao (1979)}

Solución mixta continua con losa de hormigón inferior en los fondos de los cajones en las zonas de momentos negativos y losa superior armada. (c) Consejo Superior de Investigaciones Científicas Licencia Creative Commons 3.0 España (by-nc)
Montaje de la estructura mediante empuje en curva guiado (debido a la variación del radio en planta) con las dos vigas cajón provisionalmente adosadas y empleando un pescante provisional de reducción de flechas y tensiones. Las células de las esquinas inferiores permiten la rodadura repartiendo adecuadamente las reacciones de montaje. Finalizado el empuje se efectúa el ripado de las dos vigas, el hormigonado de fondos y la ejecución del tablero desde su propia superficie, situando previamente las placas prefabricadas centrales que permiten el paso de camiones grúa que sitúan las placas laterales. Posteriormente el armado y hormigonado final de la losa conecta todos los elementos en su trabajo definitivo como sistema continuo. http://informesdelaconstruccion.revistas.csic.es 

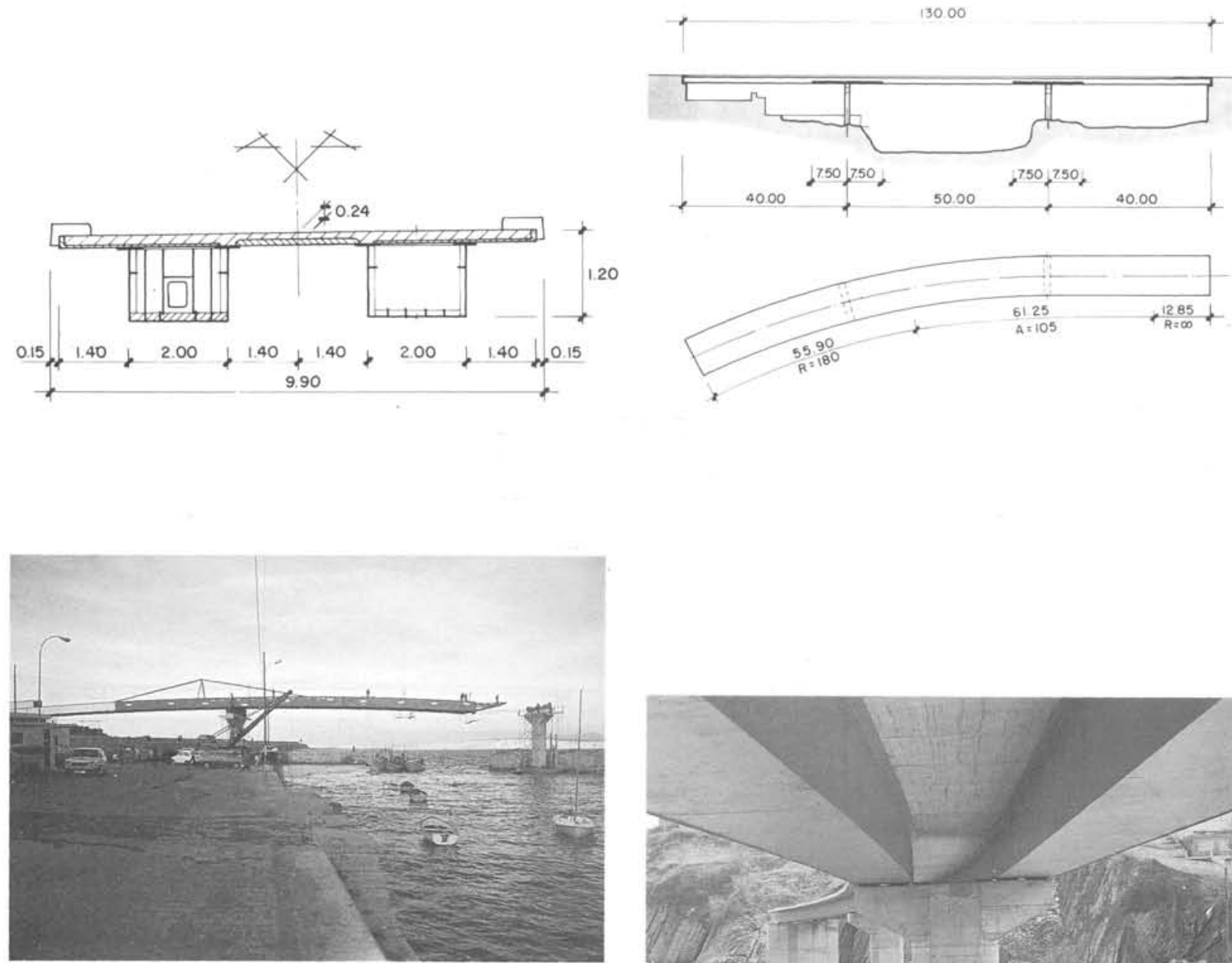

Vista desde el puerto de las últimas fases.

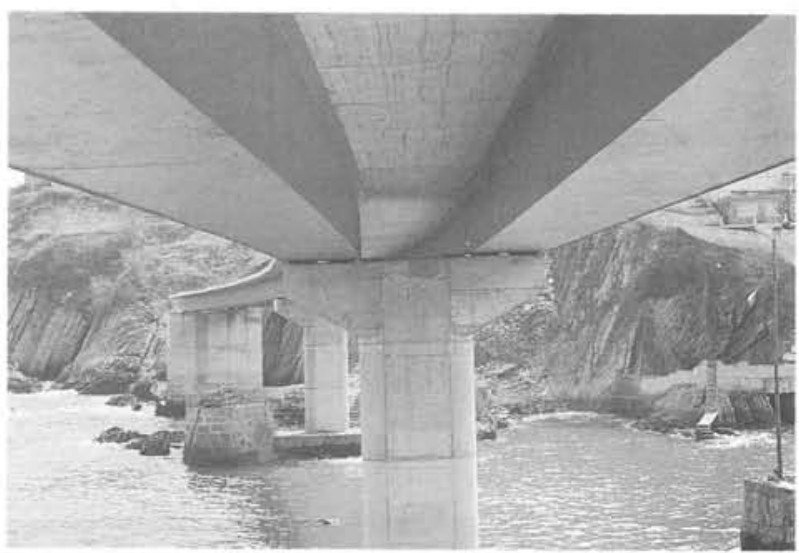

Vista longitudinal inferior.

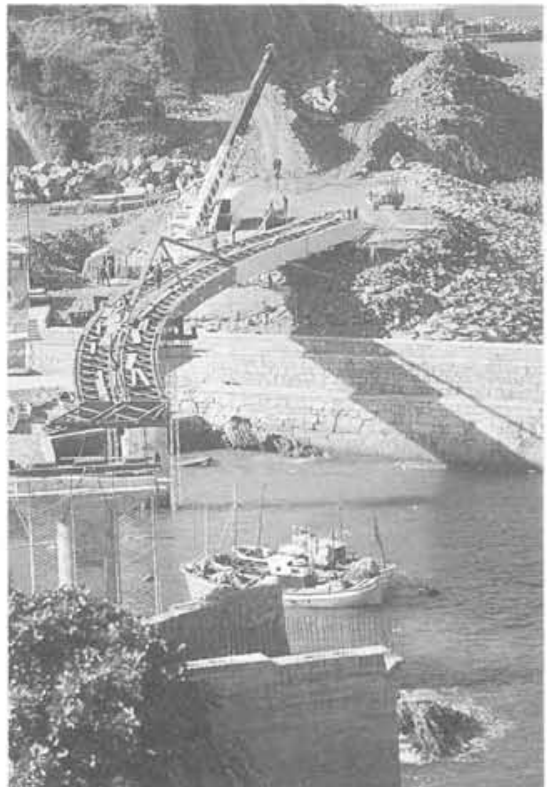

Vista aérea de la estructura de las últimas fases. 
Informes de la Construcción, Vol. 40 n. 398, noviembre/diciembre, 1988

\section{Pasos superiores gemelos sobre la CN-II Madrid (1982)}

Vigas mixtas continuas con losa de hormigón inferior en fondo de cajón en zonas de momentos negativos. Losa superior armada semiprefabricada en piezas de la anchura total del tablero. Pilas mixtas.
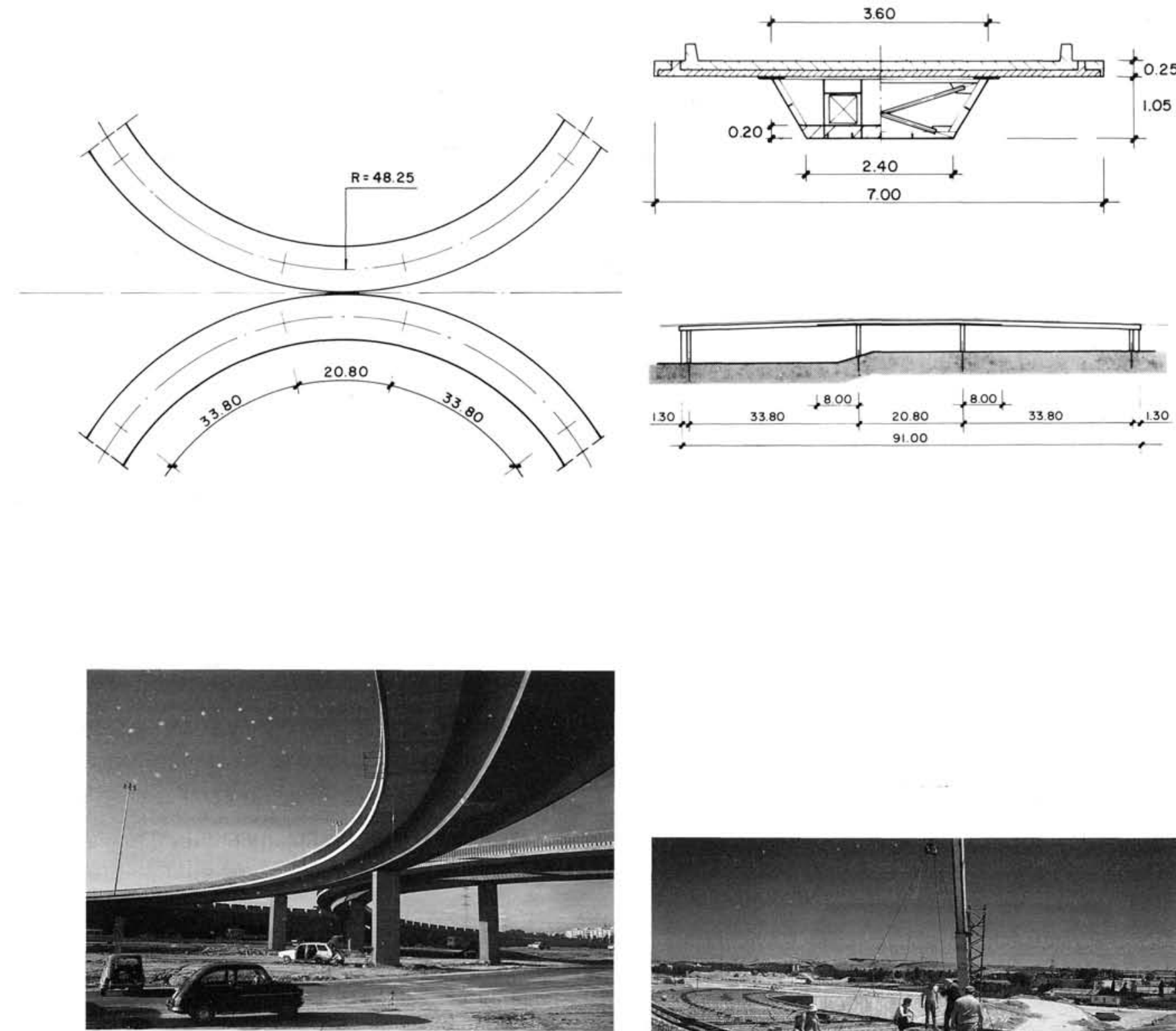

Preparación de la prueba de carga.

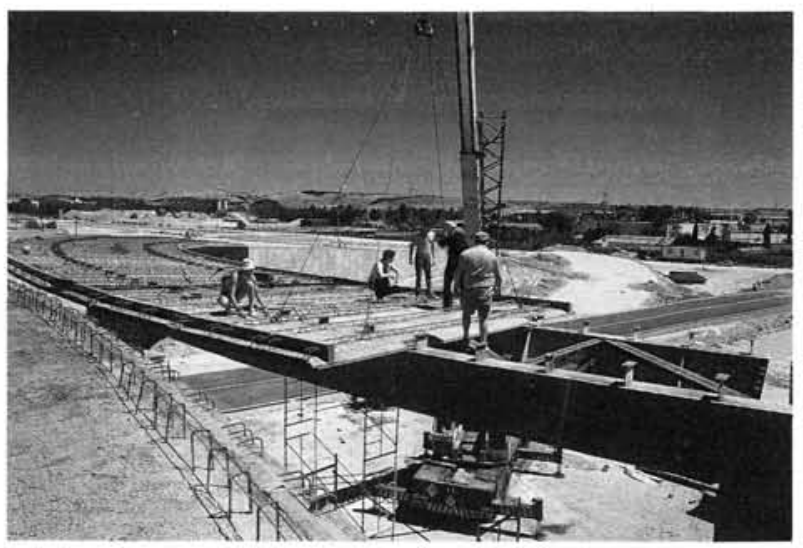

Colocación de placas en el segundo tablero. 
Puente de Marqués de Suances sobre la $\mathrm{CN}$-II en Madrid (1987)

Solución tipológica semejante a la anterior pero en doble cajón recto y con placas semiprefabricadas diferentes para zonas de voladizos y central del tablero. Pilas en solución mixta.
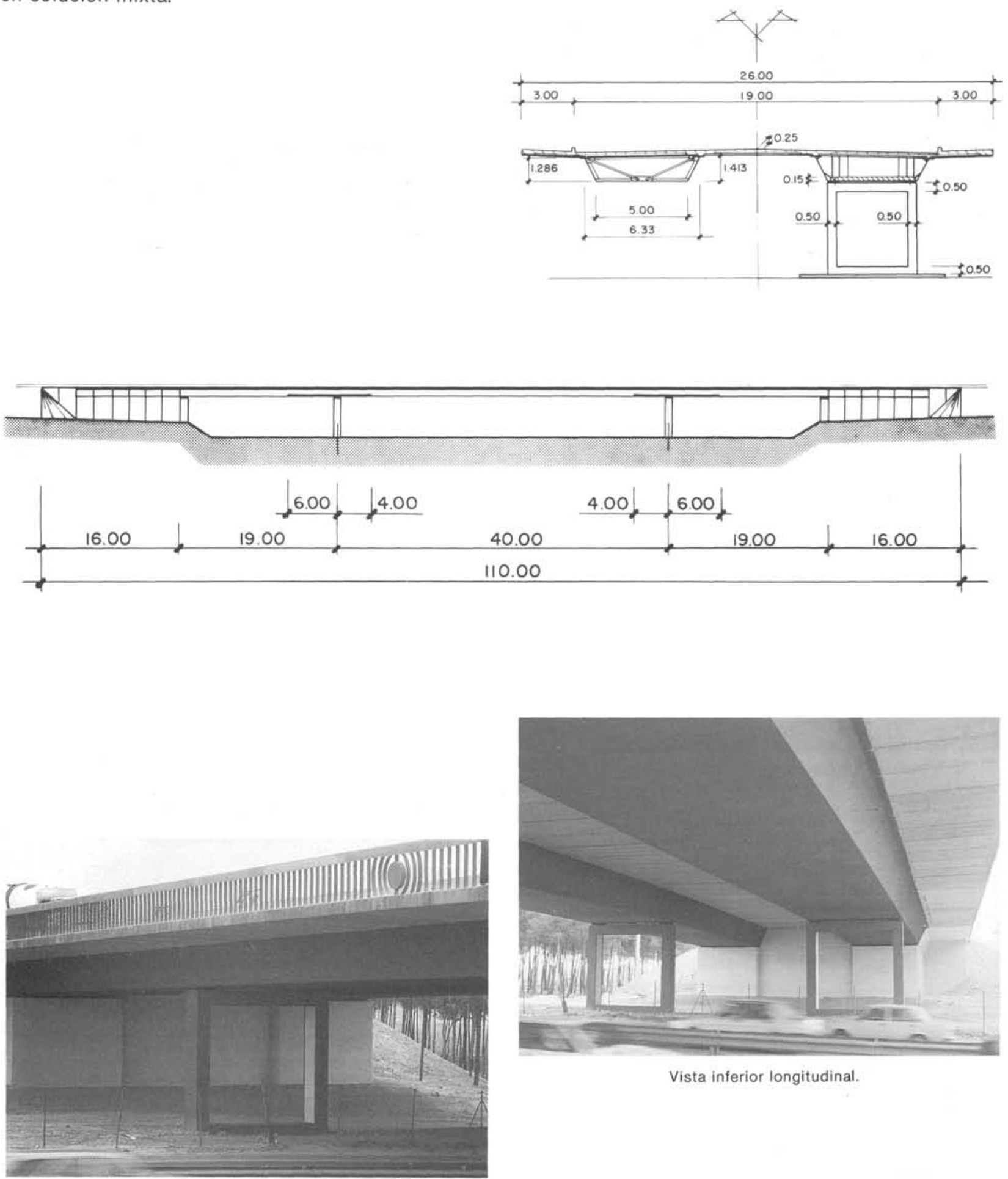

Vista inferior longitudinal.

Vista de la pila y barandilla. 


\section{Puente de Tortosa sobre el río Ebro (1988)}

Empleo combinado de grandes unidades de hormigón pretensado en zonas de pilas y dinteles mixtos pretensados en el interior de la losa superior y totalmente solidarios con los brazos de las pilas para formar un sistema aporticado.

Proceso constructivo mediante técnica de voladizos sucesivos con grandes dovelas metálicas de $60 \mathrm{t}$ de peso montadas mediante carro deslizante sobre el tablero. Losa inferior en fondo de cajón en zonas de momento negativo.

Empuje en clave de 1.200 t previo al cierre del dintel central para equilibrar y mejorar las solicitaciones permanentes en pilas y tablero.

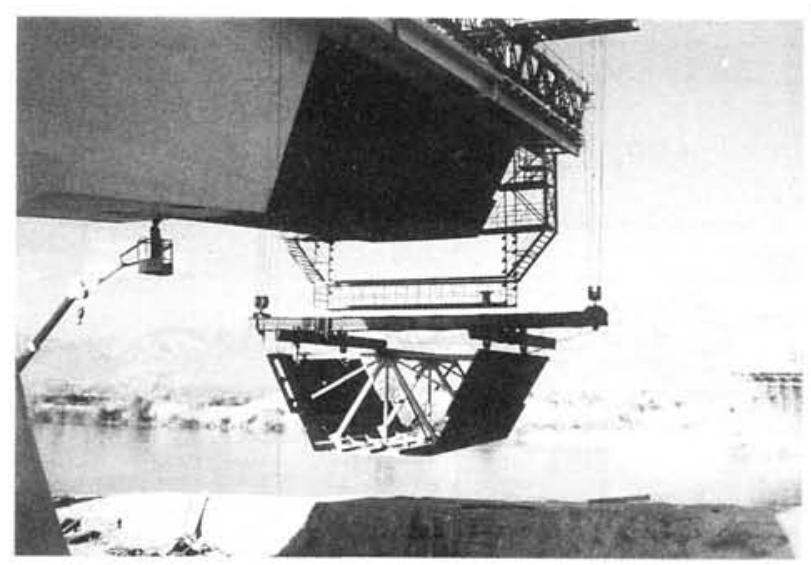

Elevación de una dovela.

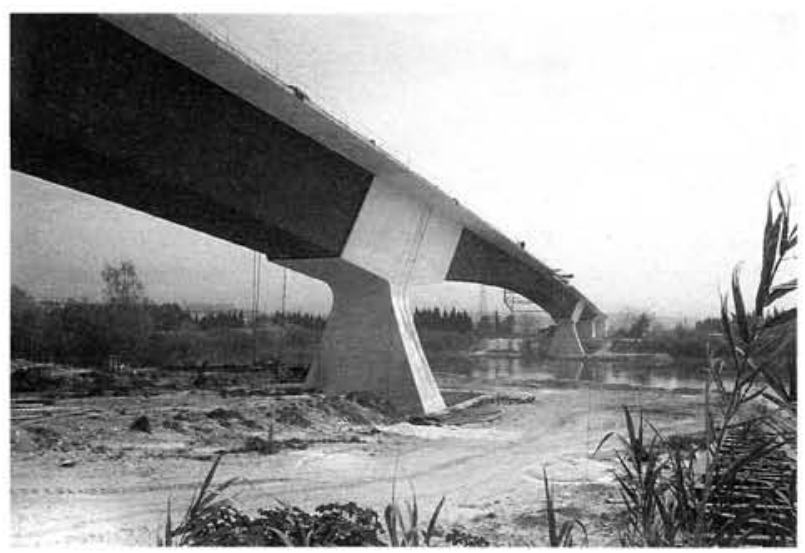

Vista diagonal en la fase final.

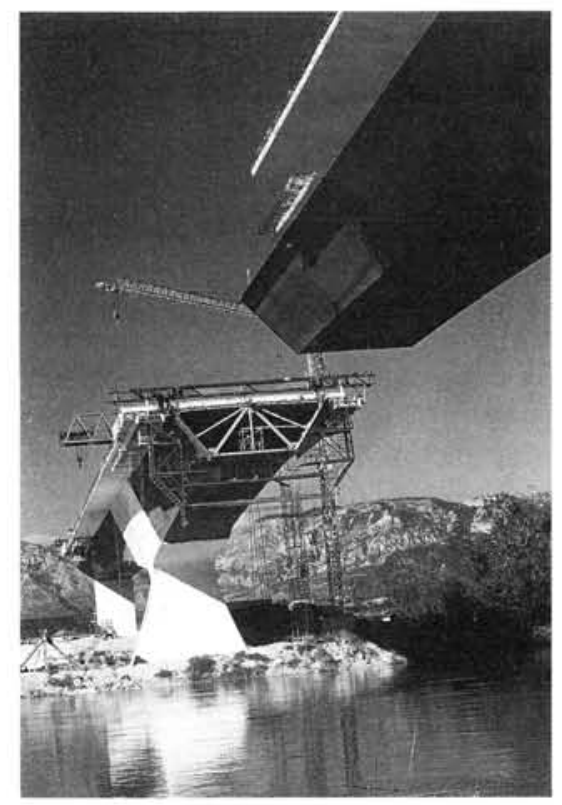

Fase intermedia de ejecución del tablero.

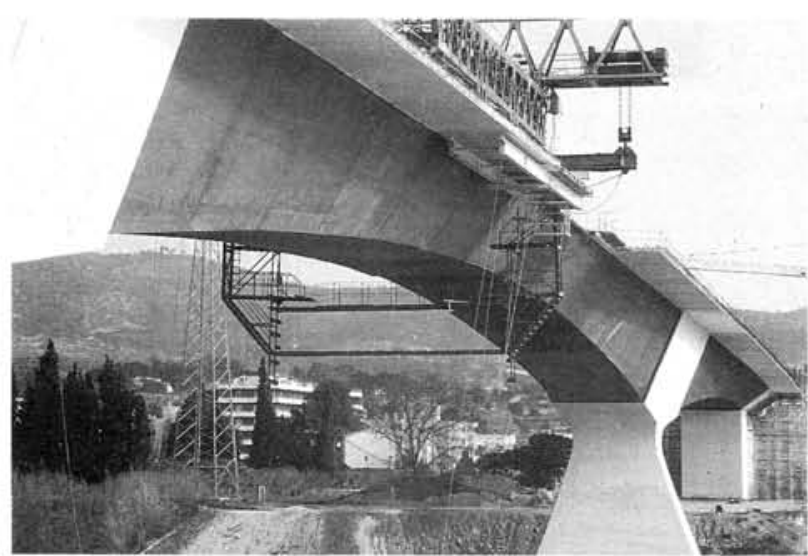

Ejecución de la fase final del tablero central. 
Puente de Tortosa sobre el río Ebro

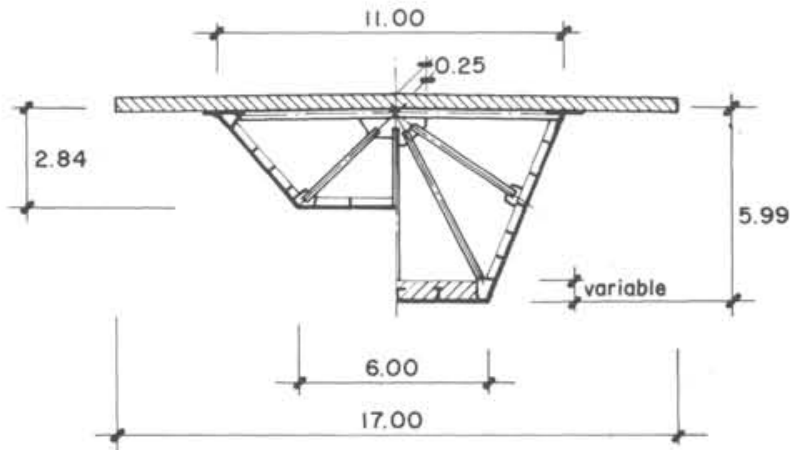

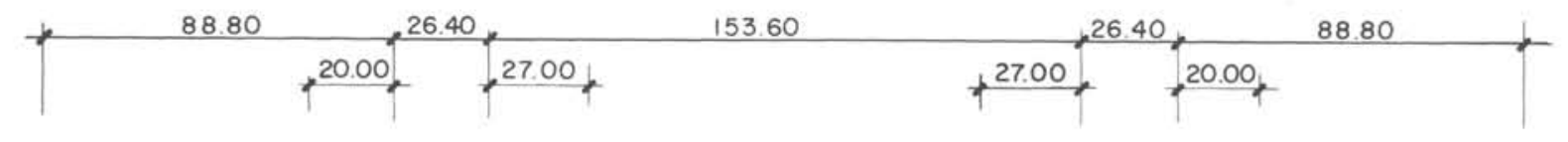

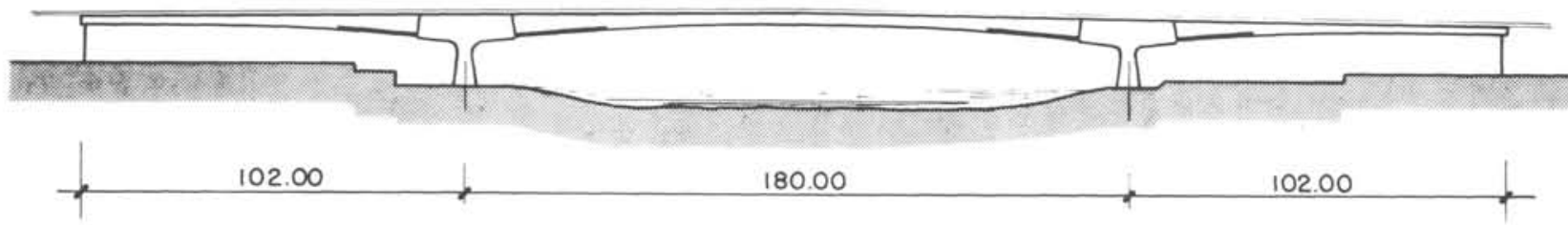

\section{USA y Canadá}

Apenas se han llevado a cabo estructuras de puentes de interés especifico, continuando de forma activa el empleo de los modelos de vigas múltiples arriostradas (en oposición al criterio europeo de dos únicas vigas en extremos de tablero), intentando corregir los problemas de fatiga detectados en las uniones superiores de dichos arriostramientos con las vigas, en las zonas de apoyos.

En el ámbito de la edificación, gran incremento del uso de los forjados de chapa plegada conectados a vigas metálicas principales de muy diversas formas y tipologias de uniones con los soportes, principalmente metálicos, para la formación de entramados.

Japón

Contribuciones aisladas en puentes, incluyéndose soluciones mixtas en algunos puentes atirantados. Los condicionantes propios de sismico, protecciones frente a la agresión marina y unas elevadas garantías de mantenimiento, determinan tipología y dimensiones poco usuales para nuestra práctica.

En la edificación, sobre todo de las grandes construcciones que su desarrollo y salida al mercado internacional asiático requieren, han dado lugar a importan- tes soluciones especificas que podrian tener interés para casos especiales, destacando el empleo de grandes vigas mixtas de celosia recubierta como dinteles de recepción de soportes; y los pórticos y pantallas antisísmico y viento ya reseñados.

\section{Conclusiones}

Considero, desde un punto de vista global y ajustado a la actual situación constructiva, que la presencia del Eurocódigo 4 abre una línea para llevar adelante una normativa española que centre los problemas y necesidades propias de la tecnologia de la construcción mixta en nuestro país.

Que los criterios teóricos y prácticos incorporados en (1) combinados con algunas reglas operativas especificas son capaces de mantener perfectamente el nivel de máxima posibilidad y exigencia de los sistemas mixtos, a la espera de las aportaciones y adaptaciones antedichas.

Que el nivel de posibilidades de la construcción mixta se mantiene intacto dentro de ciertas zonas de la construcción: grandes puentes y edificios de importancia, y aun en dominios algo menores, correspondiendo tan sólo a los técnicos y empresas constructoras el desarrollar apropiadamente líneas de estudio y ejecución adecuadamente combinadas con la construcción en hormigón, sobradamente dominada. 


\section{REFERENCIAS}

(1) "Construcción Mixta. Hormigón-Acero". Julio Martínez Calzón y Jesús Ortíz Herrera. Ed. Rueda. Madrid, 1978.

(2) Simposio sobre Construcción Mixta. Bratislava. Mayo, 1987.

(3) Conference on Composite Construction. Junio, 1987. New England College; Henniker, New Hampshire. USA.

(4) Composite Construction in Steel and Concrete. Proceedings of an Engineering Foundation Conference ASCE 1988. Editado por C. Dale Bruckner e Ivan M. Viest.

(5) "Métodos para el análisis y control automático evoluti. vo de puentes y sistemas mixtos de alta complejidad". (1987). F. Millanes y J. Martínez Calzón.

(6) "Resistencia a cortante de vigas mixtas recubiertas". J. Ortíz Herrera y J. Sancho.

(7) Draft Model Code for Composite Structures. ECCS. The Construction Press Ltd. London (1981) y "Project de Code Modéle pour Constructions Mixtes". Construction Me tallique n. 1 (Marzo 1980).

(8) Eurocode n. ${ }^{\circ}$ 4: Common Unified Rules for Composite Steel and Concrete Structures. Report EUR 9886 EM (1985).

(9) R. P. Johnson y R. J. Buckby "Composite Structures of Steel and Concrete. Volume 2". Granada Publish. Ltd. (1979).

(10) D. J. Oehlers y L. Foley "The fatigue strength of stud shear connections in composite beams". Proc. Inst. Civil Engrs., 79. (1985).

(11) K. Roik y G. Hanswille "Zur Frage der Ri $\beta$ breitenbeschränkung bei Verbundträgern". Bauingenieur 61 (1986).

(12) J.P. Lebet "Comportement des ponts mixtes acier-béton avec interaction partielle de la conexion et fisuration du béton". Ecole Polyt. Federale. Lausane (1987).

(13) A. R. Kemp "Factors affecting the rotation capacity of plastically-designed members". The Structural Engineer (Junio 1986).

(14) P. Ansourian "Plastic rotation of composite beams". Journal Engrg. Struct. Div. 108 (1982).

(15) G. W. Owen y C. B. Echeta "A semi-rigid design method for composite frames". Joints in Struct. Steel Work (1981).

(16) BS 5400, Steel, Concrete and Composite Bridges. Part 5: Design of composite bridges. British Standards Institution (1979).
(17) DIN 18806, Teil 1, Verbundkonstruktionen, Verbundstützen. Beuth-Verlag. Berlin (1984).

(18) SIA 161(2) Stahlbauten. Zürich, 1979.

(19) Richtlinien für Verbundkonstruktionen in Hochbau, 1 (1985). Sólo para edificios.

(20) Reglement de calcul des ponts mixtes acier-béton. Circular n. $81-63(1981)$

(21) SAA Composite Structures Code. Part 1 - Simply supported beams. Standards Assn of Australia, Sidney (1981).

(22) K. Van Dalen y H. Godoy "Strength and Rotational Behaviour of Composite Beam-Column Connections", Canadian Journal Civil Engr. 9 (1982).

(23) H. Robinson "Experimental Result and Calculations for Multiple Stud Shear Connections in Ribbed Metal Deck". Civil Eng. and Eng. Mechanics (1986).

(24) R. M. Schustery W. C. Ling "Mechanical interlocking capacity of Composite Slabs". Fifth Intern. Conference on Cold Formed Steel Structures". St. Louis (1980).

(25) AASHTO Guide Specification for Alternate Load-factor Design Procedures for Steel Beam Bridges Using Braced Compact Sections. (1985).

(26) "Specifications for the Design and Construction of Composite Slabs and Commentary". ASCE (1984).

(27) CSSBI "Standard for composite steel deck". Canadian Institute 1984

(28) "LRFD Specifications for the Design, Fabrication and Erection of Structural Steel for Buildings". American Institute of Steel Construction (1986).

(29) Proposed Load and Resistence Factor Design Specifjcation for Structural Steel Buildings. ASCE (1983).

(30) R. Grüter y M. Kobbner "Der Nesenbach Viadukt". Bauingenieur 60 (1985).

(31) N. Keller; R. Kahmann y M. Krips "Fuldatalbrücke Kragenhof”. Bauingenieur 63 (1988).

(32) K. Roik "Composite Road and Railway Bridges in Germany". Proceedings Engineering Foundation Conference. Henniker (1987).

(33) W. Zellner "Recent Designs of Composite Bridges". Proceedings Engineering Foundation Conference. Henniker (1987).

(34) J. C. Badoux; U. Kuhlmann y J. P. Lebet "Composite Bridge Structures". Proceedings Engineering Foundation Conference. Henniker (1987). 